(c) 2020 Universidad Nacional Autónoma de México, Facultad de Estudios Superiores Zaragoza.

Este es un artículo Open Access bajo la licencia CC BY-NC-ND (http://creativecommons.org/licenses/by-nc-nd/4.0/).

TIP Revista Especializada en Ciencias Químico-Biológicas, 23: 1-9, 2020.

https://doi.org/10.22201/fesz.23958723e.2020.0.262

\title{
Análisis de la mutación c.187 C $>$ T en el gen ATP6V0A2 mediante PCR-ARMS
}

\author{
${ }^{1}$ Carlos Alberto González-Domínguez, ${ }^{2}$ Jaime López-Valdez, \\ 1*Iván Martínez-Duncker Ramírez y ${ }^{1 * *}$ Roberta Salinas-Marín \\ ${ }^{1}$ Lab. de Glicobiología Humana y Diagnóstico Molecular, Centro de Investigación en \\ Dinámica Celular, Universidad Autónoma del Estado de Morelos; Av. Universidad \\ \# 1001, Col. Chamilpa, Cuernavaca 62210, Morelos, México, ${ }^{2}$ Departamento de \\ Genética, Centenario Hospital Miguel Hidalgo; Av. Ferrocarril S/N, Alameda, Alameda, \\ 20259, Aguascalientes, México. E-mails: *duncker@uaem.mx; **rsm@uaem.mx
}

\begin{abstract}
RESUMEN
Los desórdenes congénitos de la glicosilación (CDG) son enfermedades poco frecuentes (EPOF) de tipo metabólico y hereditarias que ocurren como consecuencia de mutaciones en los genes que codifican para proteínas que participan, directa o indirectamente, en este proceso. La enfermedad clínicamente denominada Cutis Laxa Autosómica Recesiva tipo II-A (ARCL2A) es un tipo de CDG (ATP6V0A2-CDG) causado por mutaciones en ATP6V0A2, que codifica para la subunidad a2 del dominio v0 de una ATPasa vacuolar que tiene como función el transporte de iones $\mathrm{H}^{+}$a través de las membranas celulares, regulando así el pH de los compartimentos celulares, e incluye la acidificación del aparato de Golgi. En 2014, nuestro grupo de investigación reportó por primera vez en México, la existencia de dos pacientes con ATP6V0A2-CDG. En este trabajo, se estableció una metodología para identificar a los portadores de la mutación c. $187 \mathrm{C}>\mathrm{T}$ en el ATP6V0A2 mediante PCR-ARMS.
\end{abstract}

Palabras clave: CDG, cutis laxa, ATP6VOA2, ARCL2A, PCR-ARMS.

Analysis of the c.187 C> T mutation in ATP6VOA2 by PCR-ARMS

\begin{abstract}
Congenital disorders of glycosylation (CDG) are rare hereditary metabolic diseases (EPOF) that occur as a result of mutations in the genes coding for proteins involved direct or indirectly in this process. Autosomal Recessive Cutis Laxa disease type II-A (ARCL2A) is a type of CDG (ATP6V0A2-CDG) caused by mutations in ATP6V0A2, which codes for the a2 subunit of the v0 domain of a vacuolar ATPase that has the function of transporting $\mathrm{H}^{+}$through cell membranes, regulating $\mathrm{pH}$ in cells compartments, including Golgi acidification. In 2014, our research group reported the first two cases of ATP6V0A2-CDG in Mexico. In this work, a methodology was established to identify carriers of the c. $187 \mathrm{C}>\mathrm{T}$ mutation in ATP6V0A2 by PCR-ARMS.
\end{abstract}

Keywords: CDG, cutis laxa, ATP6V0A2, ARCL2A, PCR-ARMS.

Artículo recibido el 08 de junio del 2020.

Artículo aceptado el 14 de octubre del 2020. 


\section{INTRODUCCIÓN}

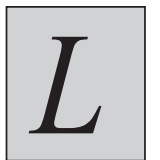

a glicosilación es un proceso enzimático co- y post-traduccional esencial para distintos procesos celulares y que consiste en la adición de carbohidratos (llamados glicanos) a lípidos y proteínas generando glicoconjugados.

La biosíntesis de los glicoconjugados de tipo $N$-, $O$ - ( $O$-manosa, $O$-glucosa, $O$-fucosa, $O$-GlcNAc ( $O$-acetilglucosamina), $O$-GalNAc ( $O$-acetilgalactosamina)), glicosaminoglicanos, proteoglicanos, glicofosfatidilinositol y glicolípidos, se lleva a cabo en el retículo endoplásmico (RE), en el citosol, en el aparato de Golgi y su red trans-Golgi (TGN) (Bobby \& Freeze 2018). La presencia de glicanos en los glicoconjugados es de suma importancia, ya que participan en el control de calidad de las proteínas, confieren estabilidad y son responsables de establecer los procesos de reconocimiento proteína/lípidoligando (Varki et al., 2017).

Las vías de glicosilación para la formación de glicoconjugados, requieren de la actividad enzimática eficiente de las glicosiltransferasas (enzimas encargadas de la adición de carbohidratos a proteínas y lípidos), de las glicosidasas (enzimas encargadas de la remoción de carbohidratos), de los transportadores de glicosil-nucleótidos (sustratos donadores) y de su disponibilidad (Varki et al., 2017).

Los desórdenes congénitos de la glicosilación (CDG) son ocasionados por mutaciones en los genes que codifican para las proteínas responsables del correcto funcionamiento de las vías de biosíntesis de los distintos tipos de glicosilación (Varki et al., 2017; Bobby \& Freeze, 2018). Los CDG pueden presentarse por mutaciones que afectan: a) la función de las glicosiltransferasas y las glicosidasas; b) el tráfico vesicular y c) la síntesis y transporte de los glicosil-nucleótidos o indirectamente cuando se altera la regulación funcional de los organelos donde se realizan los procesos de glicosilación, como por ejemplo el pH luminal, un factor importante para que las glicosiltransferasas y glicosidasas funcionen correctamente (El Ouali, Azizi, Dikhaye \& Benajiba, 2019; Varki et al., 2017; Ohtsubo \& Marth, 2006). Este es el caso del ATP6V0A2-CDG, causado por mutaciones en ATP6V0A2 (Ensembl:ENSG00000185344 MIM:611716) y que conducen a un cuadro clínico definido como Cutis laxa autosómica recesiva de tipo IIA (ARCL2A) (MIM:\#219200).

La cutis laxa es un desorden multisistémico del tejido conectivo que se caracteriza en la mayoría de los pacientes por un exceso de piel no elástica con múltiples surcos que puede desaparecer con la edad. La prevalencia de nacimiento de esta EPOF es de 1 en 1,000,000 (Orphanet, 2019) y se han descrito dos tipos: la enfermedad adquirida y la heredada. El tipo heredado o congénito puede ser desarrollado de forma autosómica dominante (ADCL), ligadaal cromosoma X(XRCL) o autosómica recesiva (ARCL tipo IA, IB, IIA, IIB, III) (Morales et al., 2011; Angelini et al., 2020).
El ATP6V0A2 (ATP6V0A2-CDG) codifica para la subunidad a2 del dominio v0 de la ATPasa de tipo vacuolar (V-ATPasa) que consta de 20 exones y 856 aa. La V-ATPasa es una bomba encargada de mantener el gradiente de concentración de $\mathrm{H}^{+}$que permite la homeostasis del $\mathrm{pH}$ en diferentes compartimentos celulares, endosomas tempranos, endosomas de reciclaje, endosomas de clasificación, vesículas secretoras y en la red trans-Golgi (TGN) donde ocurre la parte final de la biosíntesis de los glicoconjugados (Angelini et al., 2020; Casey, Grinstein \& Orlowski, 2010; Figura 1).

Las mutaciones en $A T P 6 V 0 A 2$ afectan el transporte de protones ocasionando un incremento del $\mathrm{pH}$ y la distorsión del tráfico vesicular de las proteínas. El incremento del $\mathrm{pH}$ en el Golgi, también afecta la actividad de las glicosiltransferasas generando alteraciones en los procesos de $N$-y $O$-glicosilación (Jefferies, Cipriano \& Forgac, 2008; Guillard et al., 2009; Morava et al. 2005).

En los pacientes conATP6V0A2-CDG la secreción de proteínas a la matriz extracelular se altera, particularmente la tropoelastina que es precursora de la elastina, proteína responsable de la rigidez y características elásticas de la piel. Los pacientes con ATP6V0A2-CDG presentan fontanelas grandes y con retraso en el cierre, fisuras palpebrales oblicuas descendentes, puente nasal prominente, mejillas caídas, surcos nasolabiales prominentes, voz profunda y resonante debido a la laxitud de las cuerdas vocales, divertículos, hernias, alta miopía, malformaciones corticales y cerebelares que ocasionan microcefalia, retraso en el neurodesarrollo, discapacidad intelectual y retraso del desarrollo (Morales et al., 2011; Angelini et al., 2020; Casey et al., 2010; Jefferies et al., 2008; Guillard et al., 2009; Rosnoblet \& Peanne, 2013).

Las mutaciones que afectan el funcionamiento de la V-ATPasa han sido reportadas en un gran número de pacientes provenientes de Polonia, Bélgica, China, Francia, Nueva Zelanda, Italia, Afganistán, Kuwait, Turquía, India y Reino Unido (Fischer et al., 2012; Beyens et al., 2019; Zhang-P et al., 2018). La mayoría de estos pacientes son hijos de padres consanguíneos o pertenecientes a poblaciones de baja densidad o aisladas (Fischer et al., 2012; Beyens et al., 2019; Zhang-P, Wang, Gao, Liu \& Chen, 2018). En México, se han reportado dos casos de pacientes con mutaciones distintas en el gen ATP6V0A2 provenientes de las poblaciones del Túnel de Potrerillo, Boca Túnel y Túneles en Rincón de Romos, Aguascalientes (BahenaBahena et al., 2014).

En el año 2014, nuestro grupo de investigación inició el estudio de dos pacientes con un cuadro clínico deARCL2A bajo la sospecha de un posible ATP6V0A2-CDG. Preliminarmente, se realizó un ensayo de isolectroenfoque de la $N$-glicoproteína sérica transferrina (TIEF) que demostró un perfil de hipoglicosilación tipo II para ambos pacientes, confirmando así la sospecha 


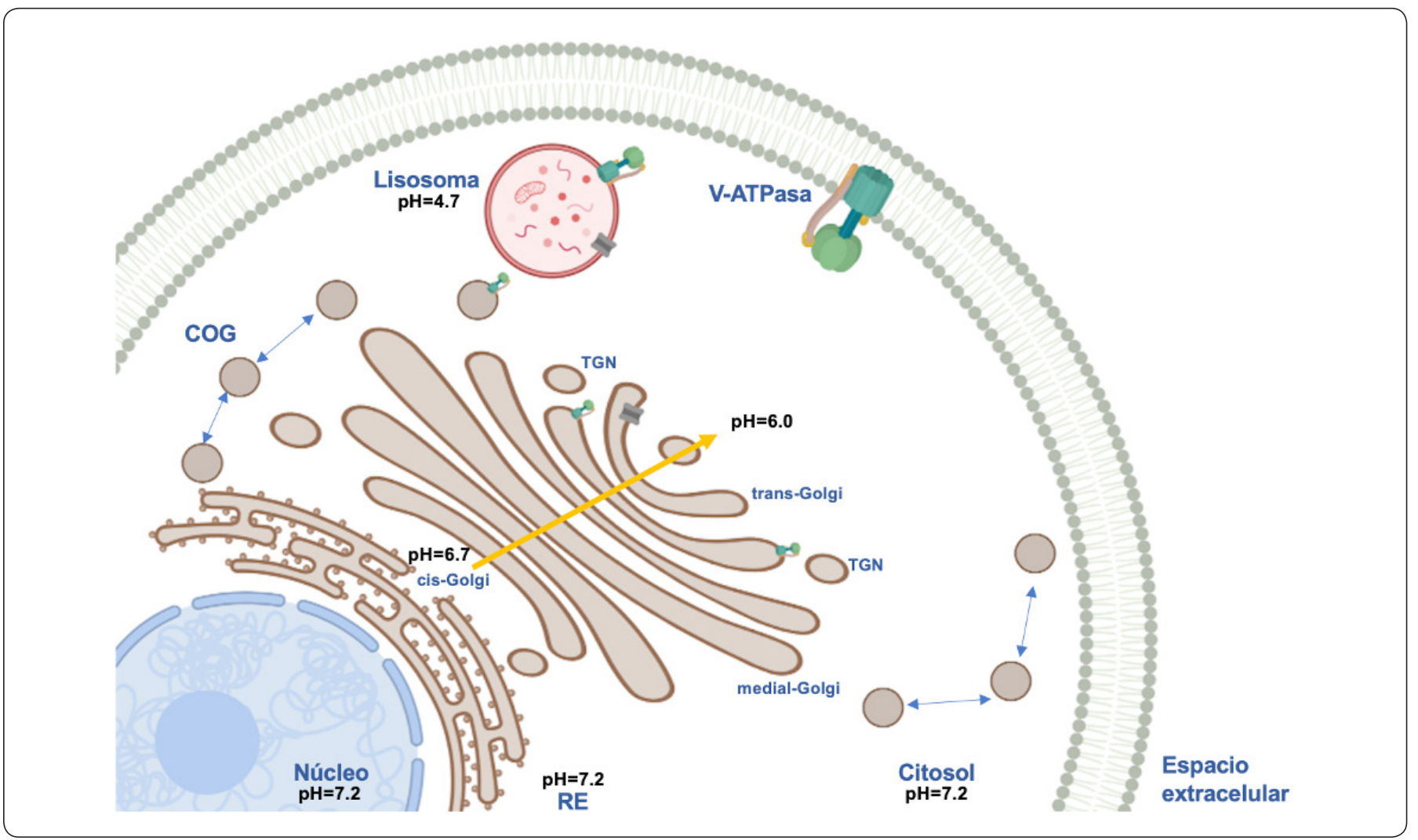

Figura 1. Ubicación celular de la V-ATPasa y pH intracelular. Cada V-ATPasa está conformada por una subunidad diferente. La ATPasa que expresa la subunidad a2 se encuentra presente en endosomas tempranos, vesículas de reciclaje, de clasificación, vesículas secretoras y en la red trans-Golgi (TGN). Es responsable de mantener el pH para el correcto funcionamiento de las vías de transporte anterógrado en el que participan el retículo endoplásmico ( $\mathrm{RE}, \mathrm{pH}=7.2)$ y principalmente las cisternas cis-, medial- y trans-Golgi en las que es importante mantener el pH de 6.7 a 6.0. La participación de la V-ATPasa en el mantenimiento de este pH se realiza en la cisterna trans-Golgi y la red TGN. Elaboración personal.

bioquímica de un CDG causado por alteraciones en el procesamiento de los glicanos en el Golgi. Esto fue confirmado por un análisis de espectrometría de masas que corroboró la deficiencia de glicosilación terminal en la glicoproteína transferrina, así como en la $O$-glicoproteína ApoCIII para el segundo paciente (Bahena-Bahena et al., 2014).

Posteriormente, se realizaron pruebas moleculares para confirmar la existencia de mutaciones en el ATP6VOA2 en ambos pacientes que provenían de dos municipios del Estado de Aguascalientes, México (Aguascalientes y Rincón de Romos). En el ADN genómico (ADNg) del paciente 1 se identificó la mutación c.187C $>\mathrm{T}$ (p.R63X) de forma homocigota en el exón 2 y en el paciente 2 se identificó la mutación c.2293C $>$ T (p.Q765X) de forma homocigota en el exón 18. Los dos individuos eran hijos de padres consanguíneos y portadores heterocigotos de las mutaciones identificadas, confirmando así la herencia autosómica recesiva (Bahena-Bahena et al., 2014).

Actualmente, el diagnóstico de estas enfermedades y la identificación de las mutaciones que las causan están sujetos al análisis molecular en centros especializados. La mayoría de estos centros no tienen una conexión directa con los pacientes, por lo tanto, es importante la implementación de una técnica rápida y accesible que permita la detección de estas mutaciones en laboratorios o centros de diagnóstico clínico.

Una estrategia accesible para la identificación de mutaciones puntuales en uno o ambos alelos del gen ATP6V0A2 es el uso de PCR-ARMS (Sistema de Mutación Refractario a la Amplificación por PCR) y sus derivadas como PCR-ARMS múltiple, T-PCR-ARMS, RT- qPCR-ARMS, qPCR-ARMS, ARMS scorpion y PCR-ARMS con hexacebadores. La PCRARMS implementada en este trabajo es una técnica derivada de la PCR convencional que requiere únicamente del diseño de 3 oligonucleótidos en contraste de sus derivadas como T-PCRARMS (4 oligonucleotidos por reacción). Para implementar la PCR-ARMS es necesario diseñar un oligonucleótido sentido, capaz de alinearse al ADNg cuando la mutación no esté presente, otro más que únicamente se alinea al $\mathrm{ADNg}$ o templado, en presencia de la mutación y un tercer oligonucleótido antisentido, utilizado con cada uno de los oligonucleótidos sentido, durante la reacción de PCR. La PCR-ARMS es aplicable en el análisis de cualquier mutación puntual conocida o polimorfismo de un 
solo nucleótido (Medrano \& De Oliveira, 2014; Saste et al., 2012; Ahlawat, Sharma, Maitra, Roy \& Tantia, 2014).

En este trabajo, se estandarizó por primera vez una metodología por PCR-ARMS capaz de discernir entre individuos no portadores, portadores y enfermos homocigotos afectados con la mutación puntual c. $187 \mathrm{C}>\mathrm{T}$ en el ATP6V0A2 con el propósito de generar una alternativa de tamizaje de portadores y de diagnóstico de ATP6V0A2-CDG.

\section{MATERIALES Y MÉTODOS Consentimiento informado}

La metodología ocupada en este proyecto fue realizada después de la obtención del consentimiento informado de cada uno de los individuos involucrados.

\section{Extracción del ADN genómico}

El ADNg se obtuvo de muestras de sangre periférica humana de individuos provenientes del municipio de Aguascalientes. La extracción del $\mathrm{ADNg}$ se realizó utilizando el kit GenElute Blood Genomic DNA (NA2010, Sigma Aldrich). En un microtubo de $1.5 \mathrm{~mL}$ se adicionaron $200 \mu \mathrm{L}$ de sangre de cada muestra y posteriormente se añadieron $200 \mu \mathrm{L}$ de solución de lisis (AL) y $13 \mu \mathrm{L}$ de proteinasa $\mathrm{K}$. La muestra se sometió a agitación de forma intensa durante 20 segundos y se incubó 10 minutos a $56{ }^{\circ} \mathrm{C}$. En el mismo tubo se agregaron $200 \mu \mathrm{L}$ de alcohol grado molecular y se agitó vigorosamente. La muestra fue colocada en una microcolumna y se centrifugó a 8,000 rpm durante 3.5 minutos descartando el volumen resultante. La microcolumna se colocó en un nuevo microtubo, se añadieron $500 \mu \mathrm{L}$ de la solución de lavado (AW1) y se centrifugó nuevamente durante 2 minutos a 8,000 rpm. En la misma microcolumna previamente utilizada se adicionaron $500 \mu \mathrm{L}$ de la segunda solución de lavado (AW2) para posteriormente centrifugar a 13,000 rpm durante 3 minutos. El resultado de la centrifugación fue decantado y se agregaron $200 \mu \mathrm{L}$ de solución de elución(AE). La microcolumna impregnada se dejó reposar durante 2 minutos y posteriormente se sometió a centrifugación a 13,000 rpm por 2 minutos y se desechó la membrana para obtener el ADNg.

\section{Cuantificación e integridad del ADN genómico}

$\mathrm{La}$ integridad de las muestras de $\mathrm{ADNg}$ purificadas fueron analizadas mediante electroforesis en gel de agarosa al 2\% (MB14402, Agarose Routine Grade) con bromuro de etidio $(0.01 \mathrm{mg} / \mathrm{mL})$. La cantidad de ADNg cargado fue de $5 \mu \mathrm{L}$ (37$75 \mathrm{ng} / \mu \mathrm{L}$ ) más $1 \mu \mathrm{L}$ de buffer de carga $6 \mathrm{X}$ a una concentración final de buffer 1X. Los geles de agarosa se corrieron a 85 Volts de manera constante en buffer de corrida TAE $1 \mathrm{X}$ y los geles se analizaron en un transiluminador de luz UV (UVP High permormance-UV Benchtop) a una longitud de onda de $260 \mathrm{~nm}$.

Las muestras de ADNg cuya integridad se verificó por electroforesis en agarosa se cuantificaron mediante espectrofotometría utilizando un NanoDrop ${ }^{\text {TM }}$ 2000/2000c
(Thermo Fisher Scientific) a longitudes de onda de $260 \mathrm{~nm}$ y $280 \mathrm{~nm}$. La cuantificación permitió obtener concentraciones en un rango de 37-75 $\mathrm{ng} / \mu \mathrm{L}$ con un factor $\mathrm{R}$ de 1.8-1.9.

\section{Diseño de oligonucleótidos para PCR ARMS}

El diseño de los oligonucleótidos se realizó utilizando la herramienta OligoCalc: Oligonucleotide properties calculator (Kibbe WA. 'OligoCalc: an online oligonucleotide properties calculator' (2007)) considerando los parámetros previamente reportados por (Medrano \& De Oliveira, 2014; Saste et al., 2012; Ahlawat et al., 2014), que sugieren puntos cruciales en el diseño de los oligonucleótidos para una PCR-ARMS. Se consideró: 1) La diferencia de temperatura de alineamiento (Tm) entre los oligonucleótidos sentido y antisentido que debe ser menor o igual a $4{ }^{\circ} \mathrm{C}, 2$ ) La secuencia de los oligonucleótidos debe iniciar y finalizar con los nucleótidos citosina (C) o guanina $(\mathrm{G}), 3$ ) Los oligonucleótidos deben tener un porcentaje de guanina y citosina promedio mínimo de $45 \%$ y máximo de $60 \%$, 4) La base mutada debe encontrarse en el extremo 3' del oligonucleótido, 5) Los oligonucleótidos diseñados no deben ser autocomplementarios o complementarios entre sí mismos y 6) El tamaño del producto de amplificación debe ser menor a $900 \mathrm{pb}$. De acuerdo con las consideraciones anteriores, se diseñó un oligonucleótido sentido normal (CGD-FIN, oligonucléotido que no reconoce la mutación, con la secuencia 5'-GAGGTGTGAAGAGCTAGAGC-3'; un oligonucleótido antisentido (CGD-HR2) con la secuencia 5'-GCACTGATCTAACACACTGGC-3'y un oligonucleótido sentido, incluyendo la mutación (CGD-FIM), con secuencia 5'-GAGGTGTGAAGAGCTAGAGT-3'.

Los oligonucleótidos diseñados permitieron amplificar la región g.6355 - g.6913 del gen ATP6V0A2 que incluye el exón 2, para lograr identificar la mutación c. $187 \mathrm{C}>\mathrm{T}$ en muestras de ADNg (Figura $2 \mathrm{~A}$ ). Los productos amplificados se observan en un gel de agarosa y el patrón esperado se esquematiza en las Figuras 2 B, 2 C y 2 D.

\section{Amplificación del $A T P 6 V 0 A 2$ en ADN genómico}

La temperatura de alineamiento o Tm de los oligonucleótidos CGD-FIN, CGD-FIM y CGD-HR2 se determinó realizando reacciones de PCR a diferentes temperaturas $60{ }^{\circ} \mathrm{C}, 62{ }^{\circ} \mathrm{C}$ y $64{ }^{\circ} \mathrm{C}$ utilizando como templado $\mathrm{ADNg}$ de un individuo sano (control) con la finalidad de evaluar el rango de temperatura específica para los oligonucléotidos diseñados para amplificar muestras de individuos sanos y portadores de la mutación. Todas las reacciones de la PCR se realizaron en una termocicladora Axygen ${ }^{\circledR}$ MaxyGene Thermal Cycler.

Las amplificaciones se realizaron por muestra de $\mathrm{ADNg}$, adicionando a un microtubo de $200 \mu \mathrm{L}$ los reactivos que se indican a continuación: $2.5 \mu \mathrm{L}$ de $\left(\mathrm{NH}_{4}\right)_{2} \mathrm{SO}_{4} 10 \mathrm{X}(750 \mathrm{mM}$ Tris- $\mathrm{HCl}, \mathrm{pH} 8.8$ a $\left.25^{\circ} \mathrm{C}\right), 200 \mathrm{mM}\left(\mathrm{NH}_{4}\right)_{2} \mathrm{SO}_{4}, 0.1 \%(\mathrm{~V} / \mathrm{V})$ Tween 20; Thermo Fisher Scientific, 00230537), $2.5 \mu \mathrm{L}$ de 


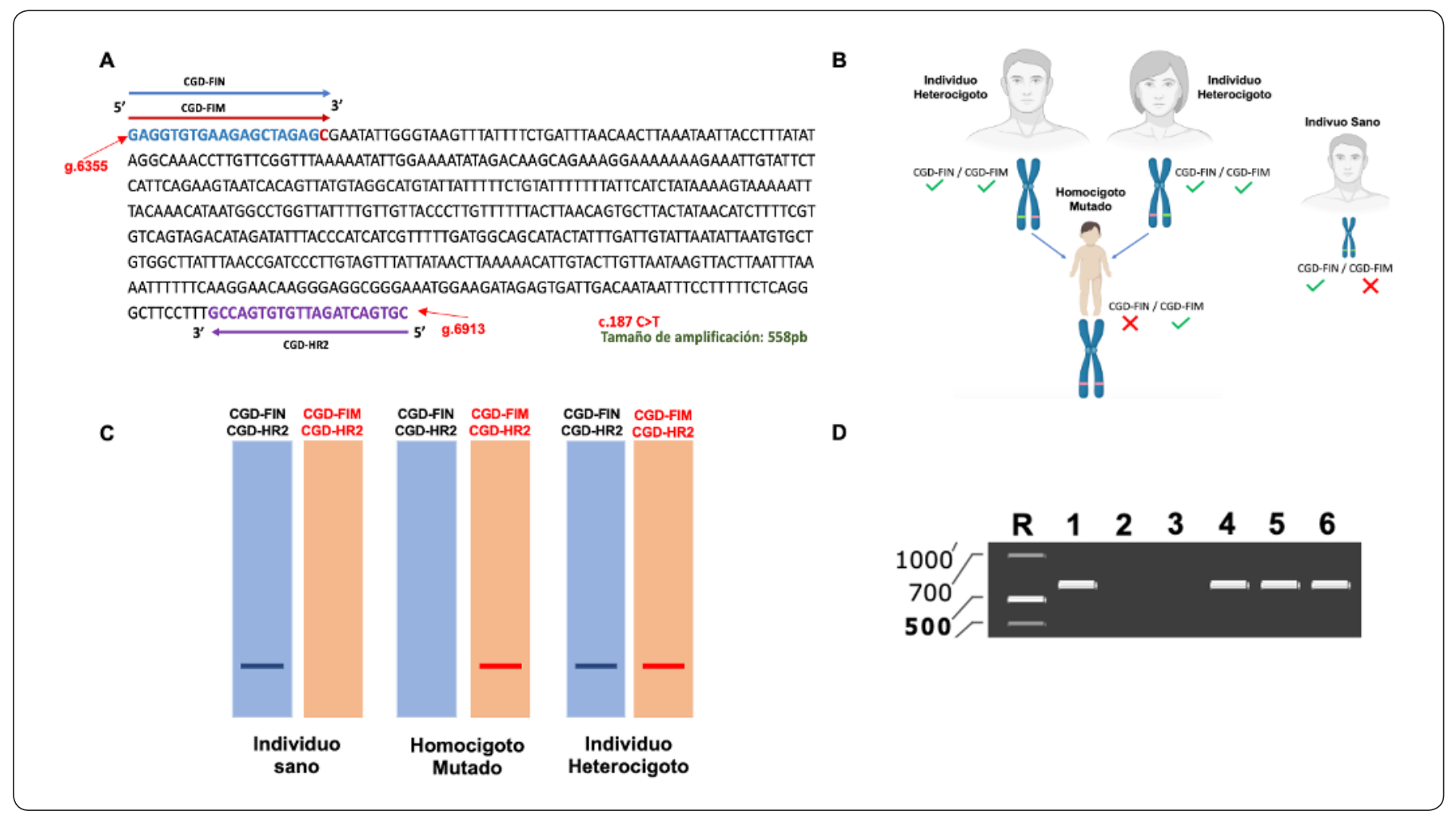

Figura 2. (A). Secuencia templado de los oligonucleótidos (CGD-FIN es el nombre clave para el oligonucleótido sentido normal y CGD-FIM es el nombre clave para el oligonucleótido sentido para la mutación) utilizados en la PCR-ARMS, para amplificar un fragmento de 558 pb del gen ATP6V0A2 utilizando el oligonucleótido anti sentido (CGD-HR2). (B). Esquema representativo para diferenciar individuos sanos, heterocigotos y homocigotos mutados. (C). Esquema de la amplificación esperada con ambos pares de oligonucleótidos utilizando el ADNg como templado, de un individuo sano, un homocigoto portador de la mutación y un individuo heterocigoto. La combinación de oligonucleótidos CGD-FIN/CGD-HR2 únicamente se alinea cuando la mutación no está presente y la pareja de oligonucleótidos CGD-FIM/CGD-HR2 se alinea cuando la mutación está presente en algún individuo analizado. (D). Representación de la amplificación en un gel de agarosa, $R$ representa el marcador de peso molecular, el patrón esperado de productos de la PCR-ARMS para un individuo sano (carriles 1 y 2), individuo homocigoto con la mutación (carriles 3 y 4) y un individuo heterocigoto (carriles 5 y 6). Elaboración personal.

$\mathrm{MgCl}_{2} 25 \mathrm{mM}$ (Thermo Fisher Scientific, 00225302), $0.5 \mu \mathrm{Lde}$ DNTP's $10 \mathrm{mM}$ (Thermo Fisher Scientific, 00342481), $0.5 \mu \mathrm{L}$ de oligonucléotido sentido $10 \mu \mathrm{M}, 0.5 \mu \mathrm{L}$ de oligonucleótido antisentido $10 \mu \mathrm{M}, 0.25 \mu \mathrm{L}$ Taq DNAPolymerase Recombinant (Thermo Fisher Scientific, \#EP0404), 17.25 $\mu$ L de $\mathrm{H}_{2} \mathrm{O}$ (DNase and Rnase free Water, Sigma Aldrich, W4502) y se adicionó 1 $\mu \mathrm{L}$ (30-70 ng/ $\mu \mathrm{L})$ de ADNg para obtener un volumen final de $25 \mu \mathrm{L}$ de reacción.

El programa utilizado en la optimización de las temperaturas de alineamiento para cada par de oligos CGD-FIN/CGD-HR2 (combinación para identificar individuos sin la mutación) o CGD-FIM/CGD-HR2 (combinación para identificar individuos portadores de la mutación) fue de $94^{\circ} \mathrm{C}$ por 5 minutos, 35 ciclos $\left(94{ }^{\circ} \mathrm{C}\right.$ por 1 minuto, gradiente de $60{ }^{\circ} \mathrm{C}, 62^{\circ} \mathrm{C}$ y $64{ }^{\circ} \mathrm{C}$ por 1 minuto y $72{ }^{\circ} \mathrm{C}$ por 1 minuto) y $72^{\circ} \mathrm{C}$ por 10 minutos.

Electroforesis de agarosa del gen ATP6V0A2

Los resultados de las amplificaciones fueron revelados en geles de agarosa (routine grade Nzytech, MB14402) al 1.5\% en $50 \mathrm{~mL}$ de buffer TAE $1 \mathrm{X}$ y $2 \mu \mathrm{L}$ de bromuro de etidio. Se cargaron $25 \mu \mathrm{L}$ de producto de amplificación con $5 \mu \mathrm{L}$ de buffer de carga $6 x$ para tener un volumen final de $30 \mu \mathrm{L}$. La electroforesis duró 80 minutos a 90 Volts constantes utilizando una fuente de poder (PowerPac ${ }^{\text {TM }}$ Basic Power Supply). Las imágenes se adquirieron en un transiluminador de luz UV de onda de $254 \mathrm{~nm}$ (UVP High permormance-UV Benchtop).

\section{RESULTADOS Y DISCUSIÓN}

En México, la existencia de pacientes con síndrome de cutis laxa lo reportó Morales-André et al., 2011, pero sin especificar el genotipo y el subtipo de cutis laxa. En 2014, nuestro laboratorio identificó los primeros dos pacientes con ARCL2A con mutaciones diferentes en el ATP6V0A2 (Bahena-Bahena et al., 2014).

El número reducido de pacientes reportados con este síndrome, no sólo se debe a su baja frecuencia, sino también a que el diagnóstico realizado es únicamente de tipo clínico e histopatológico, sin considerar la causa genética. Un factor 
importante, es que en los hospitales del interior de la república mexicana, normalmente no se realizan estudios moleculares por la falta de especialistas en el área de enfermedades genéticas o bien por falta de recursos económicos.

Nuestro grupo de investigación estableció una estrategia de PCR-ARMS, que permite discernir entre individuos no portadores de la mutación c. $187 \mathrm{C}>\mathrm{T}$, individuos heterocigotos y homocigotos del síndrome ATP6V0A2-CDG. Esta estrategia, también podría ser aplicable a otras mutaciones puntuales conocidas, evitando el uso de la secuenciación para confirmar la presencia de la mutación.

La integridad del ADNg de los progenitores del paciente y de algunas muestras del banco de $\mathrm{ADNg}$ provenientes de individuos del municipio de Aguascalientes (datos no presentados) se analizó previo a la estandarización de la metodología por PCR-ARMS.

\section{Estandarización de la PCR-ARMS en Cutis laxa por mutación en ATP6V0A2}

Un diseño ideal de oligonucleótidos para detectar mutaciones puntuales mediante la PCR-ARMS requiere que el oligonucleótido que incluye la mutación sea el antisentido, sin embargo, la secuencia de interés del ADNg del ATP6VOA2 no permitió diseñarlo con esta estrategia, debido a que no se cumplía con los requisitos previamente mencionados y reportados para esta metodología en (Medrano \& De Oliveira, 2014; Saste et al., 2012; Ahlawat et al., 2014).

La PCR-ARMS se estandarizó realizando dos mezclas de reacción de la PCR utilizando un gradiente de temperatura de 58 a $66^{\circ} \mathrm{C}$. Las temperaturas del gradiente utilizadas fueron $60{ }^{\circ} \mathrm{C}, 62{ }^{\circ} \mathrm{C}$ y $64{ }^{\circ} \mathrm{C}$ y como templado $\mathrm{ADNg}$ proveniente de un individuo sano. La primera mezcla de reacción contenía el par de oligonucleótidos CGD-FIN/CGD-HR2 para detectar individuos sanos y la otra mezcla se realizó con la combinación de oligonucleótidos CGD-FIM/CGD-HR2 para amplificar el templadoúnicamente si la mutación está presente. Los resultados obtenidos se muestran en la Figura 3 A donde se observa que las temperaturas óptimas de amplificación son de 62 y $64^{\circ} \mathrm{C}$ porque a partir de estas temperaturas se obtuvo amplificación solamente con la combinación de los oligonucleótidos CGD-FIN/CGDHR2. A la temperatura de $60{ }^{\circ} \mathrm{C}$ se observó un producto de amplificación con esta combinación de oligonucleótidos y con la combinación CGD-FIM/CGD-HR2 que reconoce la mutación puntual, sin embargo, los $60^{\circ} \mathrm{C}$ se descartaron porque el $\mathrm{ADNg}$ utilizado como templado, provenía de un individuo sano.

De la misma manera, se llevó a cabo una segunda PCR-ARMS para estandarizar la temperatura utilizando como templado ADNg del progenitor del paciente 1 (individuo heterocigoto). En esta ocasión, se obtuvo una amplificación con ambas

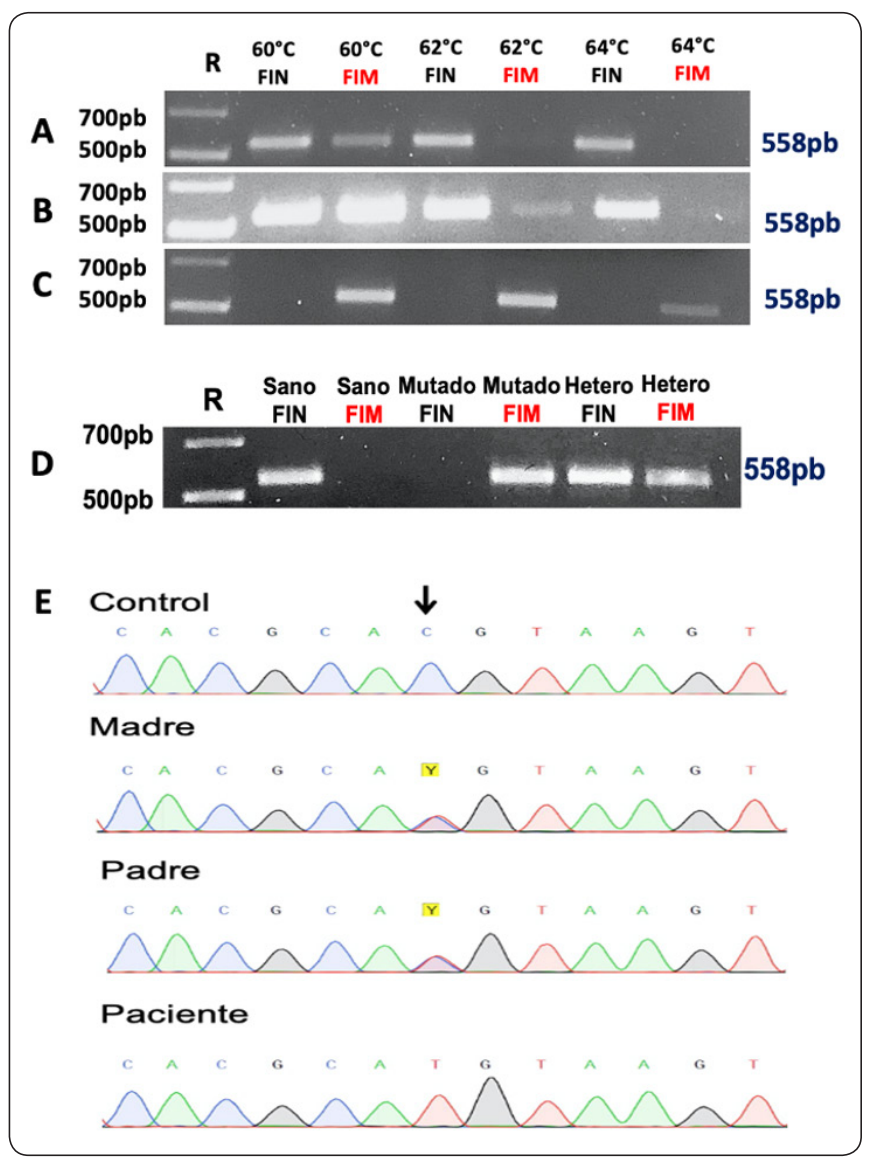

Figura 3. Productos de la PCR y secuenciación. FIN y FIM, indican la combinación de los pares de oligonucleótidos utilizados en cada reacción de la PCR (CGD-FIN/CGD-HR2 ó CGD-FIM/CGD-HR2). (A). Productos de la PCR-ARMS usado como templado ADNg de un individuo sano. (B). Resultado con la PCR-ARMS aplicando ADNg de un individuo heterocigoto (progenitor). (C). Resultado con la PCRARMS utilizando como templado ADNg del paciente 1 (homocigoto mutado).(D). Resultado con la PCR-ARMS a $62^{\circ} \mathrm{C}$ como temperatura de alineamiento y ADNg de un individuo sano, el paciente 1 (homocigoto mutado) reportado por Bahena-Bahena, et al., $2014 \mathrm{y}$ el progenitor del paciente 1 (individuo heterocigoto). (E). Secuenciación de Sanger de individuo sano, progenitores del paciente (individuos heterocigotos) y del paciente 1 (homocigoto mutado). Elaboración personal.

combinaciones o pares de oligonucleótidos como se muestra en la Figura 3 B. De acuerdo con estos resultados, es posible utilizar las temperaturas de 60 y $62{ }^{\circ} \mathrm{C}$ para amplificar templados del ADNg de individuos heterocigotos. Sin embargo, seleccionamos $62{ }^{\circ} \mathrm{C}$ como la temperatura idónea para continuar con el proceso de estandarización de la PCR-ARMS porque en individuos sanos (Figura $3 \mathrm{~A}$ ) y a $60^{\circ} \mathrm{C}$ se observó un producto de amplificación con ambas combinaciones de oligonucleótidos. La temperatura de $64{ }^{\circ} \mathrm{C}$ se descartó en esta segunda PCR-ARMS, porque no presentó amplificación con la combinación de oligonucleótidos CGD-FIM/CGD-HR2 como se esperaba al utilizar como templado muestra de $\mathrm{ADNg}$ de un individuo heterocigoto. 
Después de evaluar este resultado, se realizó una tercera PCRARMS bajo las mismas condiciones anteriormente descritas, pero ahora el templado utilizado fue $\mathrm{ADNg}$ del paciente 1 (homocigoto mutado). En la Figura $3 \mathrm{C}$, se comprueba que 60,62 y $64^{\circ} \mathrm{C}$ son temperaturas de amplificación que permiten obtener un producto de la PCR con el par de oligonucleótidos CDG-FIM/CGD-HR2, sin embargo, como ya mencionamos anteriormente, la temperatura de $60{ }^{\circ} \mathrm{C}$ se descartó porque no permite diferenciar individuos sanos de portadores de la mutación y a $64^{\circ} \mathrm{C}$ la intensidad del producto de amplificación disminuye. Los resultados obtenidos de las tres PCR-ARMS realizadas permitieron determinar que $62{ }^{\circ} \mathrm{C}$ es la temperatura adecuada para identificar la mutación puntual c. $187 \mathrm{C}>\mathrm{T}$ en ambos alelos del ATP6VOA2.

Finalmente, se realizó una PCR-ARMS con un gradiente de temperatura de 58 a $66^{\circ} \mathrm{C}$ utilizando $62^{\circ} \mathrm{C}$ como la temperatura óptima para discernir entre individuos portadores y sanos. Las muestras del ADNg del paciente 1 (homocigoto mutado), individuo sano y su progenitor (individuo heterocigoto) se utilizaron como templado con ambos pares de oligonucleótidos (CGD-FIN/CGD-HR2 y CGD-FIM/CGD-HR2). En la Figura 3 $\mathrm{D}$, se observó que realizando la PCR con los diferentes templados se obtenían amplificaciones que corresponden correctamente a lo previamente establecido. Cabe señalar, que las muestras del ADNg de un individuo sano, de los progenitores del paciente 1 (individuos heterocigotos)y del paciente 1 (homocigoto mutado) fueron previamente secuenciados (Figura $3 \mathrm{E}$ ).

Los resultados permitieron confirmar que la metodología establecida es capaz de identificar y discernir entre individuos sanos, heterocigotos y homocigotos, para la mutación c. $187 \mathrm{C}>\mathrm{T}$ en el exón 2 del gen ATP6V0A2, comprobando que la PCRARMS es una técnica que permite la diferenciación para todo tipo de mutaciones puntuales (Zhang-S et al., 2020; Zhang-R et al., 2020; Doulabi, Moghaddam \& Salehzadeh, 2020; Li, He \& Liang, 2020; Medrano \& De Oliveira, 2014)

\section{Identificación de individuos portadores de la mutación c.187 C $>$ T por PCR-ARMS}

Un lote de diez muestras de ADNg de individuos de las poblaciones de Túnel de Potrerillo, Boca Túnel y Túneles en Rincón de Romos, Aguascalientes, localidades donde se reportó por primera vez un paciente con Cutis laxa portador de la mutación c.187 C $>$ T en el exón del gen ATP6V0A2 (paciente 1) (Bahena-Bahena et al., 2014) se analizaron utilizando la metodología previamente descrita y utilizando como controles de comparación la amplificación de $\mathrm{ADNg}$ del paciente 1 y de su progenitor. Los resultados de las amplificaciones se muestran en la Figura 4.

Se identificaron 3 individuos heterocigotos (7, 9y 10) de los 10 individuos evaluados en las poblaciones de Aguascalientes. Estos resultados comprueban aún más la importancia de realizar estos

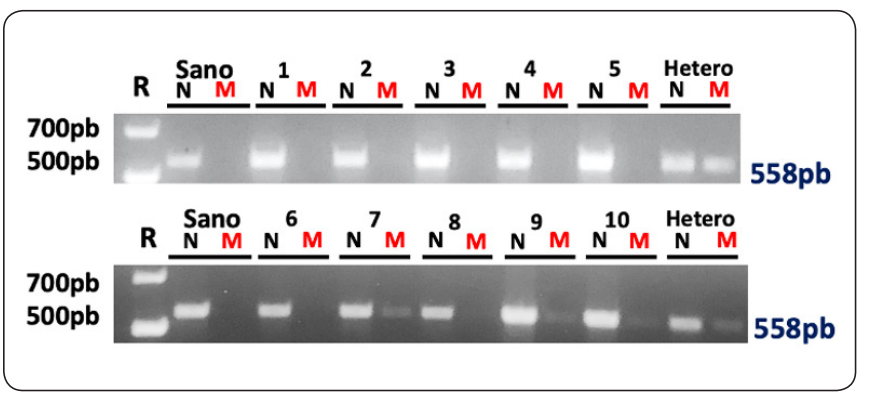

Figura 4. Análisis de diez diferentes individuos de localidades de Aguascalientes para la mutación c.187 C $>$ T en el gen ATP6V0A2 mediante PCR-ARMS. N (CGD-FIN/CGD-HR2) y M (CGD-FIM/ CGD-HR2), indican la combinación de los pares de oligonucleótidos utilizados en cada reacción con la PCR. Sano: templado de individuo sano, Hetero: templado de individuo heterocigoto (progenitor del paciente 1). Numeración de 1-10: Muestras de ADNg de individuos analizados. Elaboración personal.

estudios en localidades donde se han reportado pacientes con cutis laxa e informar a la población acerca de las indicaciones que deben seguir para disminuir la segregación de la misma. Es necesario incrementar el análisis del número de muestras con la finalidad de determinar si existen otros individuos en estas poblaciones donde la consanguinidad podría ser un factor en la incidencia de individuos heterocigotos y homocigotos, de la mutación c. $187 \mathrm{C}>\mathrm{T}$.

Aunque existen diversos métodos más sofisticados para identificar alteraciones en las vías de glicosilación como el isoelectroenfoque de glicoproteínas séricas (ej., transferrina y la ApoCIII); la espectrometría de masas y el análisis de lípidos unidos a oligosacáridos, éstos no aportan un diagnóstico genético, por lo que se requiere de secuenciación exómica o secuenciación de Sanger. Algo importante a considerar siempre en la identificación de un CDG es el cuadro clínico de los pacientes que muchas veces marca la pauta de análisis y complementa los métodos analíticos y bioquímicos previamente mencionados. El alcance de una técnica de espectrometría de masas, para identificar los cambios estructurales en una glicoproteína presente en un suero de paciente con posible CDG, así como la secuenciación exómica o de Sanger requiere de un presupuesto elevado, sobre todo si tomamos en cuenta que el análisis muchas veces se realizará únicamente para identificar a un solo individuo debido a la frecuencia de estas enfermedades raras como el ATP6V0A2-CDG.

\section{ConClusiones}

Este trabajo representa una alternativa de menor costo y mayor alcance para la detección de individuos con sospecha de ATP6V0A2-CDG porque permite identificar la presencia en estado homocigoto y heterocigoto de esta mutación puntual c.187C $>$ T del gen ATP6V0A2 sobre todo en comunidades donde existe segregación de las mutaciones por consanguinidad. 
La PCR-ARMS implementada permitió identificar 3 individuos portadores de la mutación c. $187 \mathrm{C}>\mathrm{T}$ en el exón 2 del gen ATP6V0A2 en las poblaciones donde viven los pacientes previamente reportados. Los resultados permiten inferir que hay una incidencia del 30\% en el análisis de 10 muestras de $\mathrm{ADNg}$, sin mencionar que existe la posibilidad de encontrar a otros portadores en las localidades de Aguascalientes o en otros estados de la república mexicana.

Los resultados aquí mostrados comprueban que las mutaciones en el ATP6V0A2 no solamente se encuentran en países europeos, sino que también están segregadas en poblaciones mestizas de México y son un nicho sin explorar debido a su baja frecuencia, pero que requieren de atención del sector salud para establecer su frecuencia a nivel nacional y crear un plan de atención en salud adecuado, ya que son enfermedades que ocasionan importante morbi-mortalidad.

\section{Agradecimientos}

A la Red Temática Glicociencia en Salud-CONACYT 293399 por el financiamiento para la realización de este proyecto.

\section{REFERENCIAS}

Ahlawat, S., Sharma, R., Maitra, A., Roy, M. \& Tantia, M. S. (2014). Designing, optimization and validation of tetraprimer ARMS PCR protocol for genotyping mutations in caprine Fec genes. Meta Gene, 2, 439-449. DOI: 10.1016/j. mgene.2014.05.004

Angelini, C., Thibaud, M., Aladjidi, N., Bessou, P., Cabasson, S., Colson, C., Espil-Taris, C., Goizet, C., Husson, M., Morice-Picard, F., De Sandre-Giovannoli, A. \& Pédespan, J. M. (2020). Expanding the Spectrum of Neurological Manifestations in Cutis Laxa, Autosomal Recessive, Type IIIA. Neuropediatrics, 51(4), 245-250. DOI: 10.1055/s0040-1701671

Bahena-Bahena, D., López-Valdez, J., Raymond, K., SalinasMarín, R., Ortega-García, A., Ng, B. G., Freeze, H. H, Ruíz-García, M. \& Martínez-Duncker, I. (2014). ATP6V0A2 mutations present in two Mexican Mestizo children with an autosomal recessive cutis laxa syndrome type IIA. Molecular Genetics and Metabolism Reports, 1, 203-212. DOI:10.1016/j.ymgmr.2014.04.003.

Beyens, A., Moreno-Artero, E., Bodemer, C., Cox, H., Gezdirici, A., Yilmaz Gulec, E., Kahloul, N., Khau Van Kien, P., Ogur, G., Harroche, A., Vasse, M., Salhi, A., Symoens, S., HadjRabia, S. \& Callewaert, B. (2019). ATP6V0A2-related cutis laxa in 10 novel patients: Focus on clinical variability and expansion of the phenotype. Experimental dermatology, 28(10), 1142-1145. DOI: 10.1111/exd.13723

Casey, J. R., Grinstein, S. \& Orlowski, J. (2010). Sensors and regulators of intracellular $\mathrm{pH}$. Nature Reviews Molecular Cell Biology, 11(1), 50-61. DOI: 10.1038/nrm2820

Doulabi, M., Moghaddam, R. G. \& Salehzadeh, A. (2020). Associations between an MDM2 gene polymorphism and ulcerative colitis by ARMS-PCR. Genomics \& informatics, 18(1), e9. DOI: 10.5808/GI.2020.18.1.e9

El Ouali, A., Azizi, M., Dikhaye, S. \& Benajiba, N. (2019). Cutis laxa congénital: à propos d'un cas [Congenital cutis laxa: a case study]. The Pan African medical journal, 34, 195. DOI: 10.11604/pamj.2019.34.195.17110

Fischer, B., Dimopoulou, A., Egerer, J., Gardeitchik, T., Kidd, A., Jost, D., Kayserili, H., Alanay, Y., Tantcheva-Poor, I., Mangold, E., Daumer-Haas, C., Phadke, S., Peirano, R. I., Heusel, J., Desphande, C., Gupta, N., Nanda, A., Felix, E., Berry-Kravis, E., Kabra, M. \& Kornak, U. (2012). Further characterization of ATP6VOA2-related autosomal recessive cutis laxa. Human genetics, 131(11), 1761-1773. DOI: 10.1007/s00439-012-1197-8

Guillard, M., Dimopoulou, A., Fischer, B., Morava, E., Lefeber, D. J., Kornak, U. \& Wevers, R. A. (2009). Vacuolar H+ATPase meets glycosylation in patients with cutis laxa. Biochimica et biophysica acta, 1792(9), 903-914. DOI: 10.1016/j.bbadis.2008.12.009

Jefferies, K. C., Cipriano, D. J. \& Forgac, M. (2008). Function, structure and regulation of the vacuolar $(\mathrm{H}+)$-ATPases. Archives of biochemistry and biophysics, 476(1), 33-42. DOI: 10.1016/j.abb.2008.03.025

Li, C., He, Q., Liang, H., Cheng, B., Li, J., Xiong, S., Zhao, Y., Guo, M., Liu, Z., He, J. \& Liang, W. (2020). Diagnostic Accuracy of Droplet Digital PCR and Amplification Refractory Mutation System PCR for Detecting EGFR Mutation in Cell-Free DNA of Lung Cancer: A MetaAnalysis. Frontiers in oncology, 10, 290. DOI: 10.3389/ fonc. 2020.00290

Medrano, R. F. \& De Oliveira, C. A. (2014). Guidelines for the tetra-primer ARMS-PCR technique development. Molecular biotechnology, 56(7), 599-608. DOI: 10.1007/ s12033-014-9734-4

Morales, A. M., Marinne, S., Dovala, R., Cedillos, C. A. M., Bahena, M. T., Cortés, E. R. \& Herrera, A. V. (2011). Síndrome de cutis laxa. Dermatología Cosmética, Médica y Quirúrgica, 9(1), 29-34.

Morava, E., Wopereis, S., Coucke, P., Gillessen-Kaesbach, G., Voit, T., Smeitink, J., Wevers, R. \& Grünewald, S. (2005). Defective protein glycosylation in patients with cutis laxa syndrome. European journal of human genetics: EJHG, 13(4), 414-421. DOI: 10.1038/sj.ejhg.5201361

Ng, B. G. \& Freeze, H. H. (2018). Perspectives on Glycosylation and Its Congenital Disorders. Trends in genetics: TIG, 34(6), 466-476. DOI: 10.1016/j.tig.2018.03.002

Ohtsubo, K. \& Marth, J. D. (2006). Glycosylation in Cellular Mechanisms of Health and Disease. Cell, 126(5), 855-867. https://doi.org/10.1016/j.cell.2006.08.019

Rath, A. (2020). Orphanet Versión 5.40.0. Orphanet. INSERM US14. Paris, France. Available at: https://www.orpha.net/ consor/cgi-bin/OC_Exp.php?Lng=ES\&Expert=209.

Rosnoblet, C., Peanne, R., Legrand, D. \& Foulquier, F. (2013). Glycosylation disorders of membrane trafficking. 
Glycoconjugate journal, 30(1), 23-31. DOI: 10.1007/ s10719-012-9389-y

Saste, S. R., Ghalsasi, P. M., Kataria, R. S., Joshi, B. K., Mishra, B. P. \& Nimbkar, C. (2012). ARMS-PCR as an alternative, cost effective method for detection of fecb genotype in sheep. Indian Journal of Biotechnology, 11(3), 274-279.

Varki, A., Cummings, R. D., Esko, J. D., Stanley, P., Hart, G. W., Aebi, M. \& Seeberger, P. H. (2017). Essentials of glycobiology, third edition. Cold Spring Harbor (NY): Cold Spring Harbor Laboratory Press, 823. DOI: 10.1016/ S0962-8924(00)01855-9

Zhang, P., Wang, X., Gao, Z., Liu, X. \& Chen, Q. (2018). Zhonghua yi xue yi chuan xue za $\mathrm{zhi}=$ Zhonghua yixue yichuanxue zazhi $=$ Chinese journal of medical genetics, 35(1), 100-103. DOI: $10.3760 / \mathrm{cma} . \mathrm{j}$. is sn.1003-9406.2018.01.023

Zhang, R., Tan, Y., Jian, H., Qu, S., Liu, Y., Zhu, J., Wang, L., Lv, M., Liao, M., Zhang, L., Yang, F. \& Liang, W. (2020), Anew approach to detect a set of SNP $\square$ SNP markers: Combining ARMS $\square$ PCR with SNaPshot technology. Electrophoresis, 41, 1189-1197. DOI:10.1002/elps.202000009

Zhang, S., Cai, Y., Zhang, J., Liu, X., He, L., Cheng, L. \& Cui, Y. (2020). Tetra-primer ARMS-PCR combined with GoldMag lateral flow assay for genotyping: simultaneous visual detection of both alleles. Nanoscale, 12(18), 10098-10105. DOI: $10.1039 / \mathrm{d} 0 \mathrm{nr} 00360 \mathrm{c}$ 